\title{
Safety Evaluation of Poultry Feed using Immuno Sorbent Assay Technique
}

\author{
Samanwita Banerjee* and Anil Kanaujia \\ Ayurvet research foundation-Research and Development, \\ Village Chidana, Sonipat, Haryana, India \\ *Corresponding author
}

\section{A B S T R A C T}

\section{Keywords}

Animal feed safety, Aflatoxin, Enzyme

Linked Immune

Sorbent Assay (ELISA)

\section{Article Info}

Accepted:

26 April 2020

Available Online:

10 May 2020
Food safety and security are among the major problems in the current climate of increasing population. Animal feed safety has become more of a concern since it is a potential route for hazards to reach the human food chain. Quality of feed gets compromised if raw material used in making the formulation is not properly stored and hygienic conditions during processing are not met, thus leading to production of mycotoxin contaminated feed, danger to food chain and safety. Good agricultural, storage practices and surveillance study using ELISA are the ways to keep fungal toxicity in check thereby ensuring food safety.

\section{Introduction}

Food safety and security are among the major problems in the current climate of increasing population. The global demand for agricultural crops has been increasing over the years, this development is intended, in part, to meet the rapid growth and strengthening of the livestock industry, propelled by the rising demand for livestock products .Today, world is witnessing a steady tendency in the increase of global demand for maize, wheat, soybeans etc., and their products due to the steady growth and strengthening of the livestock industry.
Thus, animal feed safety has gradually become more important, with mycotoxins representing one of the most significant hazards. The three main genera of fungi producing mycotoxins are Aspergillus, Fusarium, and Penicillium. Among various type of mycotoxins, aflatoxins (AFs) are highly toxic and are known to contaminate a wide variety of foods. AFs are produced by Aspergillus species, namely $A$. flavus, $A$. nomius and $A$. parasiticus (Dipendra K. Mahato et al., 2019).

Animal feed safety has become even more of a concern for both producers and 
governments since feed consumption is, eventually, a potential route for hazards to reach the human food chain (Fig.1). In accordance with the Directive 2002/32/EC, the quality and safety of products intended for animal feed must be assessed prior to their use in feed to ensure that they do not represent any danger to human health, animal health or the environment, or do not adversely aff ect livestock production (Carolina Santos Pereira et al., 2019).

The U.S. Food and Drug Administration (FDA) have stipulated guidelines for the maximum aflatoxin level for poultry feed (Table-1).

In recent years, number of poultry farms have cropped up in district Sonipat, Panipat and Jind of Haryana who also manufacture feed for their birds using their own knowledge or taking consultancy from experts. Quality of feed gets compromised if raw material used in making the formulation is not properly stored and hygienic conditions during processing are not met, thus leading to production of mycotoxin contaminated feed, danger to food chain and safety.

Ayurvet Research Foundation is an ISO 9001:2015 certified organization, having its own DSIR, Ministry of Science and Technology, Govt. of India approved state of the art R\&D Centre, well equipped with and sophisticated instrumentation facility to take up the issues concerning food safety apart from research on Anti-Microbial Resistance (AMR), animal health and nutrition, waste to wealth management, soil and water health, quality control of medicinal plants etc. A pilot scale study was carried out at the centre to analyze the total aflatoxins content of raw material used in manufacturing of poultry feed, finished formulation using ELISA (Enzyme Linked Immunosorbent Assay technique and educating the manufacturer about the importance of use of good quality raw material, maintaining proper storage and hygienic conditions for better farm profits and ensuring food safety.

\section{Materials and Methods}

\section{Collection of samples, preparation and extraction}

50 poultry feed samples (250gm each) were collected from different poultry farms of Panipat, Sonipat and Jind district of Haryana, India. All were ground to fine powder that passes through 20 mesh sieved. $5 \mathrm{gm}$ of each grounded sample was extracted with $25 \mathrm{ml}$ of $70 \%$ methanol and filtered through Whatman no. 1 filter paper and collected the filtrate.

\section{Estimation of aflatoxin}

The screening of the total aflatoxin present in the feed samples was done as per the methodology using AOAC approved ELISA kit. Four standards of total aflatoxin $(5 \mathrm{ppb}-$ $50 \mathrm{ppb}$ ) and negative control was used for the preparation of calibration curve (Fig:2 and 3). The principle is based on direct competitive ELISA techniques in a microwell format which allow the user to obtain exact concentration in parts per billion (ppb), free aflatoxin and the controls are allowed to compete with enzyme labeled aflatoxin (conjugate) for the antibody binding sites. Repeatedly washed the well with the distilled water and added substrate which resulted in production of blue colour after the reaction with conjugate. Added stop buffer to individual well to terminate the reaction. The optical density was read at $650 \mathrm{~nm}$ using microwell reader. Calculation was done by using Neogen's Veratox software.

\section{Results and Discussion}

High concentration of the aflatoxin content in feed samples being fed to the animal lead to 
severe health hazards such as nervous system breakdown, liver and kidney toxicity, etc. to animal as well as indirectly to the human being. According to the World Trade Organisation (WTO) the permissible limit of aflatoxins for feed and food products should be 4-20 ppb (Usha P. Sarma et al., 2017). Among 50 feed samples analyzed, the total aflatoxin content was found to be in the range of $1.48 \mathrm{ppb}-94.02 \mathrm{ppb}$ in Table-2. Out of 50 samples, 18 samples (36\%) were found to comply FDA guideline and contained less than 20ppb whereas rest 32 samples (64\%) were found not complying to guideline and contain total aflatoxin above $20 \mathrm{ppb}$.

Practically it is hard to prevent aflatoxin contamination in food and feed commodities. Infestation with pathogenic fungi as well as mycotoxin can happen in any step of pre harvesting or post harvesting, processing, handling, shipment and storage under favorable environmental conditions. Good agricultural and storage practices, enforcing strict food safety standards, educating consumers and farmers, promoting better livestock feeding and management, and creating general awareness about personal protection, are some of the ways to control aflatoxins.

Animal feed safety has become more of a concern for both producers and governments since feed consumption is, eventually, a potential route for hazards to reach the human food chain. Quality of feed gets compromised if raw material used in making the formulation is not properly stored and hygienic conditions during processing are not met, thus leading to production of mycotoxin contaminated feed, danger to food chain and safety.

The screening of the total aflatoxin present in the poultry feed samples collected from different poultry farms of Panipat, Sonipat and Jind district of Haryana, India, was done at ARF R\&D centre as per the methodology using AOAC approved ELISA kit. Out of 50 samples, 18 samples (36\%) were found to comply FDA guideline and contained less than 20ppb whereas rest 32 samples (64\%) were found not comply to guideline and contain total aflatoxin above $20 \mathrm{ppb}$.

Table.1 Maximum permissible limits as per FDA

\begin{tabular}{|l|l|l|}
\hline For & Level & Commodities \\
\hline Human & $20 \mathrm{ppb}$ & $\begin{array}{l}\text { all food except } \\
\text { milk }\end{array}$ \\
\hline All Animal Species & $20 \mathrm{ppb}$ & all feed \\
\hline $\begin{array}{l}\text { Exceptions } \\
\text { Breeding cattle, breeding swine, } \\
\text { mature poultry }\end{array}$ & $100 \mathrm{ppb}$ & corn \\
\hline All animal species & $300 \mathrm{ppb}$ & $\begin{array}{l}\text { cottonseed meal } \\
\text { used in feed }\end{array}$ \\
\hline
\end{tabular}


Table. 2 Screening of selected poultry feed having aflatoxin concentration above $20 \mathrm{ppb}$

\begin{tabular}{|l|c|c|c|}
\hline Feed Sample & Total aflatoxin (in ppb) & Feed Sample & Total aflatoxin (in ppb) \\
\hline Sample 1 & 21.52 & Sample 17 & 66.87 \\
\hline Sample 2 & 32.69 & Sample 18 & 27.06 \\
\hline Sample 3 & 80.23 & Sample 19 & 39.41 \\
\hline Sample 4 & 42.19 & Sample 20 & 36.39 \\
\hline Sample 5 & 62.33 & Sample 21 & 48.32 \\
\hline Sample 6 & 25.56 & Sample 22 & 28.15 \\
\hline Sample 7 & 64.79 & Sample 23 & 94.02 \\
\hline Sample 8 & 92.88 & Sample 24 & 51.18 \\
\hline Sample 9 & 38.53 & Sample 25 & 43.50 \\
\hline Sample 10 & 35.69 & Sample 26 & 23.96 \\
\hline Sample 11 & 29.70 & Sample 27 & 21.17 \\
\hline Sample 12 & 50.11 & Sample 28 & 27.82 \\
\hline Sample 13 & 72.15 & Sample 29 & 55.30 \\
\hline Sample 14 & 35.60 & Sample 30 & 46.28 \\
\hline Sample 15 & 38.66 & Sample 31 & 37.72 \\
\hline Sample 16 & 28.72 & Sample 32 & 73.21 \\
\hline
\end{tabular}

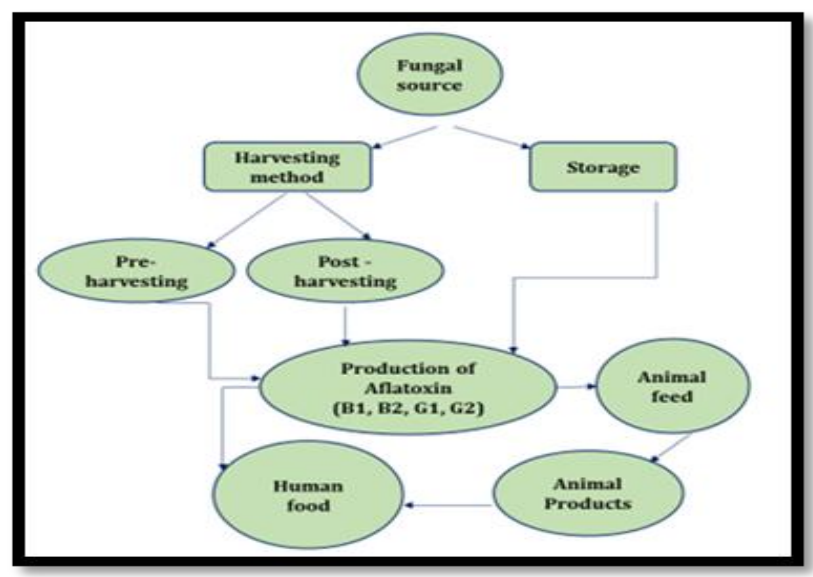

Figure.1 Aflatoxin pathways in food chain

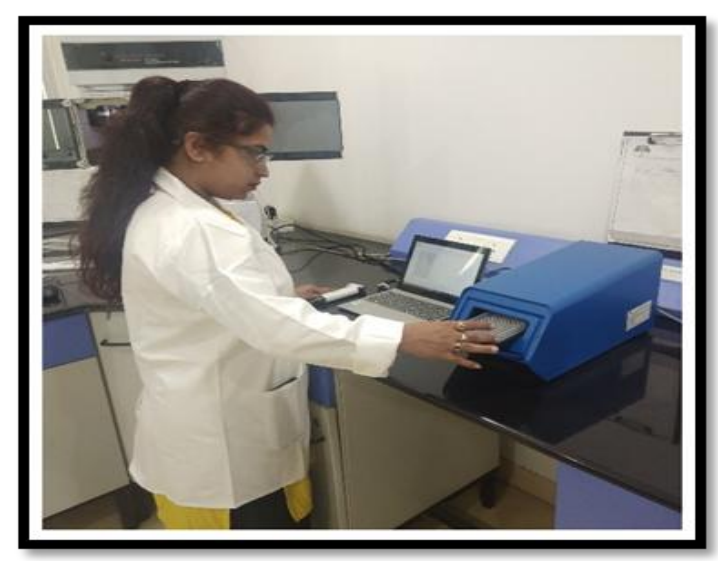

Figure.2 Quantification of aflatoxin using ELISA 


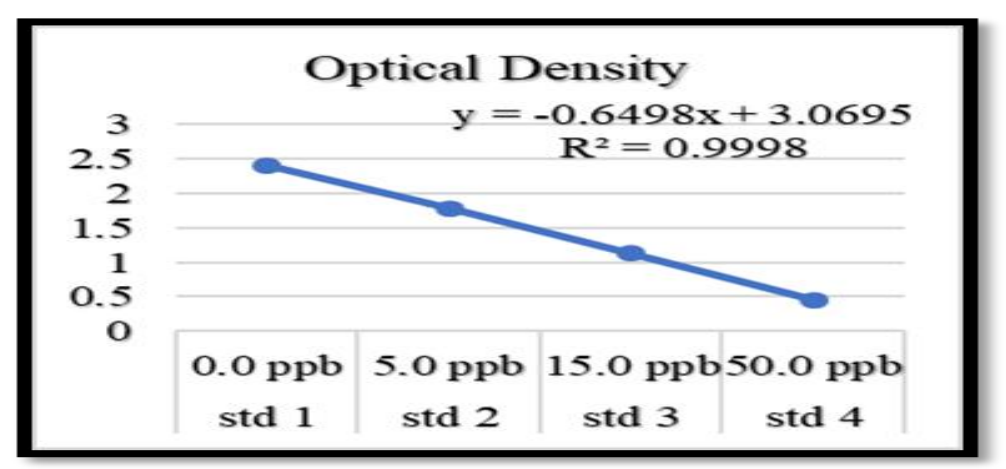

Figure.3 Regression curve of aflatoxin standards using ELISA

Practically it is hard to prevent aflatoxin contamination in food and feed commodities. Good agricultural and storage practices, enforcing strict food safety standards, educating consumers and farmers, promoting better livestock feeding and management, and creating general awareness about personal protection, are some of the ways to control aflatoxins.

Awareness is being created among the poultry feed manufacturers of the region about proper handling and storage of the feed and food grains to prevent fungal infestations and improvement in farm profits.

\section{Acknowledgements}

The authors are thankful to $\mathrm{Mr}$. Mohan Ji Saxena, Managing Trustee, Ayurvet Research Foundation, for providing guidance and facilities to conduct this research work.

\section{References}

Carolina Santos Pereira, Sara C. Cunha,José O. Fernandes,2019, Prevalent Mycotoxins in Animal Feed: Occurrence and Analytical Methods,Toxins11,290;doi:10.3390/to xins11050290.

Dipendra K. Mahato, Kyung Eun Lee, MadhuKamle, Sheetal Devi, Krishna N. Dewangan, Pradeep Kumar and Sang G.Kang, 2019, Aflatoxins in Food and Feed: An Overview on Prevalence, Detection and Control Strategies, Frontiers in microbiology, https://doi.org/10.3389/fmicb.2019.02 266).

Sec. 683.100 Action Levels for Aflatoxins in Animal Food, FDA guidelines, https://www.fda.gov/media/121202/do wnload

Usha P. Sarma, PreetidaJ.Bhetaria, Prameela Devi \& Anupam Varma, 2017, Aflatoxins: Implications on Health, Indian Journal of Clinical Biochemistry, 32(2): 124-133.

\section{How to cite this article:}

Samanwita Banerjee and Anil Kanaujia. 2020. Safety Evaluation of Poultry Feed using Immuno Sorbent Assay Technique. Int.J.Curr.Microbiol.App.Sci. 9(05): 3531-3535. doi: https://doi.org/10.20546/ijcmas.2020.905.420 